\title{
Preface to the MME Special Issue on Emerging Technologies/Fourth Industrial Revolution in Mining
}

\author{
Jürgen F. Brune ${ }^{1}$
}

Received: 30 June 2019 / Accepted: 30 June 2019 / Published online: 15 July 2019

(C) Society for Mining, Metallurgy \& Exploration Inc. 2019

The Fourth Industrial Revolution, that of digital technologies and their application, is rapidly impacting the mining industry, as it is manufacturing, transportation, agriculture, trade, and most other industries.

Mining is about 40,000 years old and has its origins in Africa. Since its earliest days, it has experienced four distinct "revolutions" that each resulted in significant improvements in production, productivity, and safety and health: The First Revolution in the fifteenth through eighteenth centuries brought technologies that improved miners' lives and health, including pumps, forced and mechanical ventilation with wind catchers and bellows, the wire rope and black powder, to name a few. Many simple, muscle- or water-driven machines have been pictured and described in great detail by Agricola who wrote De Re Metallica in 1556. Agricola was familiar with, and concerned about, accidents where miners fell off rotten, wooden ladders, acrid smoke, and dust that caused respiratory illnesses and diseases. He also knew the dangers of fatigue and recommended that miners should sing aloud to prevent them from falling asleep.

The invention of the steam engine in nineteenth-century Britain set off the Second Industrial Revolution - mechanization: first in manufacturing and agriculture, and soon, in mining. Powerful steam and electric hoists, ventilation fans, and dewatering pumps enabled deeper mining and gave access to a new bounty reserves. Early in the twentieth century, many countries established mine safety authorities and research organizations to prevent catastrophic mine fires, explosions, and collapses. Advances in ventilation and dust control have greatly improved explosion safety and respiratory health while mechanical and hydraulic roof support has improved stability and reduced the hazards of rock falls and miners trapped in collapsed workings.

Jürgen F. Brune

jbrune@mines.edu

1 Colorado School of Mines, Golden, CO, USA
The Third Industrial Revolution, mass mining, occurred in the twentieth century and brought us fully mechanized loading, hauling, conveying and processing, and increased production and productivity by orders of magnitude. Joseph Joy patented his coal loading machine in 1919. The Joy loader is still used today and, while it made the job easier, it also replaced dozens of miners who had been hand-loading in backbreaking labor. The continuous miner eliminated blasting as it was able to cut the coal with rotating picks. Bucket-chain and bucket-wheel excavators enabled true continuous mining and eliminated the batch process of loosening, loading, and hauling, at least in soft rock. Mechanized drills revolutionized the blasting process, while high explosives made blasting more effective compared with black powder.

In the Fourth Revolution, digital and wireless communication technologies have enabled big data analytics, sensors that measure machine health in terms of voltages, currents, temperatures, flows, and vibration and report this information to remote diagnostic computers or human troubleshooters. Wired digital trunk lines brought computers to the mining faces in the late 1990s and today, wireless technologies are widely used to track vehicles and miners both in surface and underground mines. Automation has come a long way in smartly controlling conveyors during start-up and shut-down phases, eliminating long run-up phases with empty belts and spill-overs during emergency stops. Many mines use fully automated haul trucks that require little to no human interaction as they spot next to the shovel, navigate the haul roads, and dump their loads in the correct location, guided by a computerized dispatch system. Fully autonomous trucks and trains have increased production capacity by 10 to $20 \%$ in the Australian Pilbara mining region.

Mining jobs will change as digitalization permeates our industry. Miners and engineers must become familiar with sensors, communications, algorithms, and programs that will control equipment and mines of the future. Virtual and augmented reality (VR and $A R$ ) will be used to visualize orebodies, ventilation conditions, remote-controlled equipment, and its operating state. VR and AR also make great 
training and teaching aids as they take the student from the classroom into the mine and even right into the mining machine. Gamification will be used to influence human behavior: miners will compete online to earn points for safe and healthy behaviors by using a smart phone app rather than follow Safe Work Instructions written on paper.

Just as automotive assembly lines use robots to weld, lift, fit, and bolt together components, robots will control mining machines and make them safer by removing the operators from the hazards of dust, noise, and proximity to heavy machinery. Human interaction will increasingly focus on monitoring and fine tuning automated and autonomous processes and troubleshooting when things go wrong. In a 2016 study funded by Dell, 20 business and technology experts world- wide concluded that $85 \%$ of jobs required by 2030 did not yet exist. Yes, such extrapolations into the future should be taken with some skepticism but we should expect a rapid, exponential increase in new job types and skills required - and someone needs to teach these skills. The year 2030 is only 10 years away! To quote Wayne Gretzky: Today's miners must skate where the puck is going to be in five to 10 years. Expect the mining world to move fast, and be ready for a wild ride.

Jürgen F. Brune, P.E.

Section Editor-in-Chief, Mining

Publisher's Note Springer Nature remains neutral with regard to jurisdictional claims in published maps and institutional affiliations. 